\section{Reasonable doubt?}

SIR-George F. Wood's letter (Nature 341,$100 ; 1989$ ) suggests that some of your readers may not be aware of the legal profession's understanding of certain "issues involving probability". A substantial body of case law and commentary addresses the two issues he identifies. On the question of "what probability represents the 'reasonable doubt' beloved of the legal profession", see, for example, Branion v. Gramly, 855 F.2d 1257, 1263 n.5 (7th Cir. 1988) ("reasonable doubt means 0.9 or so, with adjustments depending on the gravity of the offense"); J. Kaplan Stanford L. Rev. 20, 1065-1092 (1968). On the "purely statistical" proof of an elevation in "death rates due to ... external circumstances", see, for example, Sindell v. Abbott Laboratories, 26 Cal. 3d 588, 163 Cal. Rptr 132, 607 P. 2d 924 (1980); D. Kaye Am. Bar Fdn Res. J. 487-516 (1982).

Center for the Study of Law,

D. H. KAYE

Science and Technology, Arizona State University,

Tempe,

Arizona 85287-0604, USA

\section{No paying twice}

SIR--Henry Gee's News item (Nature 342,$110 ; 1989$ ) correctly explains the background and purpose of the programme of the European Science Foundation (ESF) on the molecular neurobiology of mental illness. ESF is asking for FF10 million (\$1.6 million) from its member organizations to run this programme for five years. Clearly this sum will not pay for all of the science involved; in each ESF country, the cooperating scientists will have to use normal national routes to raise the research funds required.

The ESF's FF10 million will be spent largely on coordination: interchange between scientists, collection of new pedigrees, computer services and the initiation of Southern blot analysis of chromosomal regions outside the normal interests of mental illness specialists, to ensure complete mapping of the genome.

There can of course be no question of anyone "paying twice" for the same work - no ESF member organization would do that.

Gee reports the concern of scientists about two points. First, I can reassure colleagues that the formal code of practice of the programme contains provisions for allotting particular regions of the genome to research groups that can justify a deep involvement with that region. Otherwise allotment will be 'random' to ensure both fairness and complete coverage of the genome. Second, the data facility of the programme will not perform any linkage analysis unless help is specifically requested by the members supplying the data.

We hope that this programme will help to identify innate risk factors in mental disease and provide a tool for the refinement of psychiatric diagnosis. These are high ambitions; to further them, we must of course satisfy both our professional colleagues and the proper concerns of funding organizations. We believe we are doing so.

JAQUES MALLET

CNRS Laboratoire de Neurobiologie

Cellulaire et Moléculaire,

Gif-sur-Yvette, France

\section{Purge the bombers}

SIR-The problem of terrorist bombings of airplanes in flight might be solved by a simpler and possibly more effective means than large, expensive thermal neutron analysers (TNAs). Specifically, the solution can make use of the elementary principle in chemistry that oxidation, including spontaneous combustion of plastic explosives, requires oxygen. Exclusion of oxygen, rather than or in addition to bombs, from airplane cargo holds could be accompanied by purging with nitrogen, an inert, completely non-toxic and nonpolluting gas comprising nearly 80 per cent of the Earth's atmosphere. Perhaps more realistically, the large bins used to contain checked passenger luggage could be purged, and the purge maintained through slow release of nitrogen from a liquid or (small and safe) compressed source within each bin.

This proposal to exclude oxygen from luggage bins can be economically implemented in airports of even the most technologically non-advanced nations. The universal problem of flight delays would be turned into a benefit by providing time before airplane take-off for nitrogen substantially to replace oxygen within each piece of luggage. To function, a terrorist bomb would have to carry its own oxygen supply, or use air contained within hermetically sealed luggage to support an exclusion of sufficient intensity to breach the nitrogen-purged luggage bin, whereupon the explosion could accelerate by using air in the cargo hold, assuming it has not also been nitrogen-purged. It should be easy to scan luggage for hermetic sealing and/or the presence of compressed oxygen. Nonetheless, it would be desirable to identify any or all conditions under which single pieces of luggage could carry sufficient non-compressed oxygen to sustain explosions of the intensity required to breach nitrogen-purged luggage bins.

In airports equipped with TNAs, nitrogen-purging can address the problem of unacceptably frequent false-positive TNA scans. Instead of manually searching numerous items of luggage yielding positive TNA scans, such luggage could be placed in nitrogen-purged bins, with some obvious trade-offs. As a final point, the feasibility of this low-technology solution can be tested in the short term, before major resources are committed to developing costlier high-technology solutions to be available only in the more distant future.

ROBERT A. Michaels

Ram Trac Corporation

931 Northumberland Drive,

Schenectady,

New York 12309, USA

\section{Nobel infallibility}

SIR-The debate over the fairness or otherwise of the award of this year's Nobel Prize for Physiology or Medicine is reminiscent of the controversy over the 1952 prize for the discovery of streptomycin. This was awarded to Selman Waksman alone, specifically for his discovery of the antitubercular antibiotic streptomycin. Streptomycin was in fact discovered by one of Waksman's research students, Albert Schatz. Schatz had senior authorship on the main papers that announced the discovery and also appeared on the streptomycin patents. In addition, Waksman and others signed sworn affidavits to the effect that Schatz was co-discoverer. Finally, following a lawsuit, Schatz was legally defined as streptomycin's co-discoverer.

When Schatz's colleagues learned that Waksman alone was to be awarded the Nobel Prize for streptomycin, they began lobbying to correct the injustice. Some leading scientists, including William Feldman, sympathized with Schatz, but felt it politic not to intervene on his behalf. Amazingly, in reply to probing on Schatz's behalf, the committee that had awarded the prize admitted that it had never heard of Schatz. So much for the investigative abilities of the Nobel prize committees. It seems that nothing much has changed over the past 30 years or so. Indeed, the rules of the prize mean that no corrections can be made; essentially the Nobel committees regard themselves as infallible, and do not admit to mistakes. Stehelin should be warned that the scientific establishment does not take kindly to the Nobel prize boat being rocked. The career of Albert Schatz was blighted by his attempts to gain due recognition for his work. We can only hope that the same fate does not befall Stehelin

Department of Molecular Biology

M. WAINWRIGHT and Biotechnology,

University of Sheffield,

Sheffield, S10 2TN, UK 